\title{
CRM v javnem sektorju: Kaj se lahko naučimo iz izkušenj zasebnega sektorja?
}

UDK: $65.012: 35.004 .13$

\author{
Nina Tomaževič
}

Fakulteta za upravo, Univerza v Ljubljani

nina.tomazevic@fu.uni-lj.si

\section{IZVLEČEK}

Rezultati uspešne uvedbe sodobnih konceptov menedžementa v poslovnih okoIjih ter potreba po posodobitvi delovanja javnega sektorja so v razvitih državah pospešili uporabo novih pristopov $k$ izboljševanju učinkovitosti javnega sektorja. Eden izmed njih je koncept ravnanja odnosov s strankami (CRM-Customer Relationship Management). Prispevek obravnava področje in izkušnje $z$ ravnanjem odnosov $s$ strankami v zasebnem sektorju ter prikazuje možnosti uporabe tega koncepta v javnem sektorju.

Ključne besede: javni sektor, menedžment $v$ javnem sektorju, reforme javnega sektorja, usmerjenost k strankam, ravnanje odnosov s strankami

\section{Uvod}

Razmere $\vee$ svetovnem gospodarstvu zahtevajo od držav, da poleg uspešnega in učinkovitega zasebnega sektorja razvijejo in izboljšujejo tudi konkurenčen javni sektor. $V$ evropskem prostoru so bili za to področje postavljeni cilji $\vee$ lizbonski strategiji. Zaradi navedenih razlogov se mnoge razvite države lotevajo reform javnega sektorja, ki jih na kratko lahko opredelimo kot "premišljene spremembe struktur in procesov $v$ organizacijah javnega sektorja $\mathrm{s}$ ciljem, da delujejo bolje« (Pollit, Bouckaert, 2004, str. 8).

Večina reform javnega sektorja vsebuje elemente in izkušnje za doseganje uspešnosti in učinkovitosti poslovanja iz primerov poslovanja podjetij v zasebnem sektorju. Po navedbah Tekavčičeve (Tekavčič, 2004, str. 31, 32) se organizacije, ki delujejo $v$ tistem delu javnega sektorja, kjer je njihova dejavnost $v$ veliki meri prepuščena tržnim načelom (predvsem je to pogosto $\vee$ ZDA), hitro prilagajajo in $\vee$ svoje poslovanje vse bolj uvajajo prijeme, ki so se sicer uveljavili $\vee$ zasebnem sektorju, predvsem $\vee$ proizvodnih organizacijah. Okoliščine zahtevajo, da jim 


\section{Nina Tomaževič \\ CRM v javnem sektorju: Kaj se lahko naučimo \\ iz izkušenj zasebnega sektorja?}

sledijo tudi javni sektorji držav v razvitem delu Evrope, medtem ko se v Sloveniji ta proces odvija zelo počasi, predvsem zaradi pomanjkanja ustrezno usposobljenih menedžerjev.

Tudi deli slovenskega javnega sektorja se bodo morali slej ko prej prilagoditi spremembam $\vee$ okolju in začeti spreminjati miselnost ter uporabljati sodobne koncepte menedžmenta. Cilj prispevka je predstaviti koncept ravnanja odnosov s strankami, ki se je razvil v poslovnem svetu, ter poskušati njegove značilnosti in prednosti povezati z izboljšavami procesov in struktur $v$ javnem sektorju.

Prispevek je sestavljen iz petih delov. $V$ prvem obravnavamo pojem menedžmenta in reform $v$ javnem sektorju, $v$ drugem pa sodobna orodja za izboljšanje uspešnosti in učinkovitosti poslovanja, poznana iz zasebnega sektorja. Tretji del opisuje koncept ravnanja odnosov s strankami $v$ zasebnem sektorju, ki ga $v$ četrtem delu povežemo $s$ trendi $\vee$ javnem sektorjem, da lahko $v$ petem delu koncept prenesemo tudi na javni sektor.

\section{Menedžment in reforme $v$ javnem sektorju}

Pečar (Pečar, 2002) navaja, da so v 80-ih letih prejšnjega stoletja v razvitih državah začeli ugotavljati, da bi lahko tudi $\vee$ javnem sektorju uporabili številne izkušnje, spoznanja, tehnike in metode sodobnega menedžmenta ter sorodnih področij in tehnologij, kljub temu, da se javni sektor $v$ določenih značilnostih in zakonitostih delovanja razlikuje od zasebnega. Iskati so začeli odgovore na vprašanja, kot so:

- Ali se lahko javni sektor toliko spremeni, da bi bil sposoben uporabljati dognanja sodobne znanosti s področja menedžmenta?

- Kakšne morajo biti spremembe, da bo uporabnik javnih storitev enako pomemben, kot je kupec $v$ pogojih tržne ekonomije?

- Kako izboljšati kakovost javnih storitev?

- Kako doseči tekmovalnost in inovativnost v javnem sektorju?

Sodoben javni sektor naj bi bil torej rezultat reform, ki so se jih lotile mnoge države, da bi dosegle znižanje javnih izdatkov pri hkratnem ohranjanju obsega storitev ter izboljšale kakovosti le-teh. Navedene cilje je možno doseči s pomočjo sprememb na naslednjih področjih (po Klun, 2002, str. 20):

- usmerjenost k rezultatom in spodbujanje tekmovalnosti

- usmerjenost k uporabnikom

- prenova delovnih procesov 
- prenova struktur organiziranosti (decentralizacija) in razmejitev odgovornosti

- novi načini vodenja, sprememba organizacijske kulture

- uporaba sodobnih tehnologij.

Rezultati sprememb na navedenih področjih naj bi bile kakovostnejše in cenejše storitve, ki jih javni sektor nudi državljanom in gospodarskim subjektom, znižanje stroškov delovanja javnega sektorja in povečanje zadovoljstva vseh uporabnikov storitev javnega sektorja. Javni sektor naj bi dosegel večjo učinkovitost z izvajanjem načel strokovnosti, politične nevtralnosti, objektivnosti, transparentnosti in profesionalnosti.

\section{Sodobna orodja za izboljšanje uspešnosti in učinkovitosti poslovanja}

Podjetja v zasebnem sektorju razvitega sveta (ZDA, Japonska, Evropa) že desetletja uporabljajo različna orodja za izboljšanje kakovosti procesov poslovanja in posledično uspešnosti ter učinkovitosti. Predvsem $v$ ZDA že dlje časa, $\checkmark$ Evropi pa $\vee$ zadnjih letih uvajajo podobne koncepte tudi organizacije $\vee$ javnem sektorju. $V$ vseh primerih gre za poskuse iskanja novih rešitev za povečanje uspešnosti poslovanja $\vee$ sodobnem poslovnem okolju, ki od različnih vrst združb zahteva doseganje poslovne odličnosti (Tekavčič, 2004, str. 34).

Med omenjene koncepte za izboljšanje poslovanja, bodisi na področju vodenja kakovosti, trženja, ekonomike in financ ali ravnanja z ljudmi pri delu, sodijo naslednji primeri:

- TQM (Total Quality Management - celovito ravnanje kakovosti)

- Benchmarking (primerjanje z najboljšimi)

- CRM (Customer Relationship Management - ravnanje odnosov s strankami)

- ERP (Enterprise Resource Planning - celovite programske rešitve)

- $\quad$ BSC (Balanced Scorecard - model uravnoteženih kazalnikov)

- $A B C$ (Activity Based Costing - stroški po aktivnostih poslovnega procesa)

- BPR (Business Process Reengineering - celovita prenova poslovnih procesov)

- KM (Knowledge Management - ravnanje z znanjem). 


\section{Nina Tomaževič \\ CRM v javnem sektorju: Kaj se lahko naučimo \\ iz izkušenj zasebnega sektorja?}

\section{Koncept ravnanja odnosov strankami - CRM'}

$\checkmark$ zasebnem sektorju se je trženje $v$ 90-ih letih prejšnjega stoletja znašlo $v$ krizi, saj so bila tržišča zasičena z izdelki in storitvami številnih proizvajalcev oziroma ponudnikov, rast trgov je upadla, vpliv tržnih znamk je bil omejen na posamezne segmente. Stranke so postale zahtevnejše in vse bolj osveščene, za vloženi čas in denar zahtevajo vedno več in le najboljše, težje jih je prepričati le z oglasnimi sporočili, zavedajo se svoje kupne moči, zato se je spremenil tudi odnos ponudnikov do strank. Tradicionalni trženjski pristopi ne prinašajo več želenih rezultatov, še posebno na področju trženja storitev in medorganizacijskega trženja. Pomemben prispevek $k$ upadu pomena trženjskega spleta pa nekateri avtorji, na primer Postma (Postma, 2001, str. 94-96), pripisujejo povečanju uporabe elektronskih komunikacij.

Tabela 1: Spremembe v okolju, ki vplivajo na povečanje pomena in vpliva strank

\begin{tabular}{|c|c|}
\hline preteklost & sedanjost in prihodnost \\
\hline množičnost & posameznik \\
\hline splošno & posamično \\
\hline omejena izbira & izobilje \\
\hline tiskani mediji & elektronski mediji \\
\hline pasivnost strank & interaktivnost med stranko in ponudni- \\
kom storitev
\end{tabular}

Prirejeno po: Postma, 2001, str. 94-97

Spremembe $v$ okolju od gospodarstvenikov zahtevajo nove pristope, saj obstoječi, kot sta na primer trženjski splet (4P) in transakcijsko trženje (osredotočenost na enkratne ekonomske transakcije in poudarjeno iskanje novih strank), ne prinašajo želenih rezultatov. Zato se je pojavil nov koncept, in sicer ravnanje odnosov s strankami, ki na odnos s posamezno stranko gleda kot na dolgoročno sodelovanje in vzpostavljanje obojestransko koristnih odnosov med združbo, njenimi strankami, zaposlenimi in drugimi deležniki.

1 Okrajšava CRM je v svetovnem in slovenskem poslovnem svetu že dobro uveljavljena, zato bo na nekaterih mestih, predvsem tam, kjer je mišljena $v$ ožjem smislu (kot tehnologija), uporabljena kar v svoji originalni obliki, na drugih pa $v$ obliki slovenskega prevoda poimenovanja celotnega koncepta. 
Tabela 2: Primerjava starega in novega koncepta trženja

\begin{tabular}{|c|c|}
\hline transakcijsko trženje & ravnanje odnosov s strankami \\
\hline usmerjenost na posamezno transakcijo & usmerjenost na ohranjanje strank \\
\hline občasni stiki s strankami & neprekinjen stik s strankami \\
\hline pomembne so lastnosti izdelkov & pomembna je vrednost stranke \\
\hline kratkoročni sistemi za kontrolo & dolgoročni sistemi za kontrolo \\
\hline poudarek na storitvi za stranko je majhen & poudarek na storitvi za stranko je velik \\
\hline $\begin{array}{c}\text { omejena pripravljenost zadovoljevati } \\
\text { pričakovanja stranke }\end{array}$ & $\begin{array}{c}\text { velika pripravljenost zadovoljevati } \\
\text { pričakovanja stranke }\end{array}$ \\
\hline kakovost je skrb zaposlenih v proizvodnji & \begin{tabular}{c} 
kakovost je skrb vsakega zaposlenega \\
\hline
\end{tabular}
\end{tabular}

Prirejeno po: Egan, 2001, str. 24

Koncept ravnanja odnosov s strankami (CRM) se uporablja $v$ dveh različno širokih pomenih, bodisi $\vee$ ožjem pomenu kot programska oprema bodisi kot koncept celovite poslovne strategije, usmerjene $k$ zadovoljevanju potreb strank. Za resen pristop $k$ izboljšavam $v$ poslovanju je torej potreben pogled na CRM kot na celovito poslovno strategijo, saj bo $v$ nasprotnem primeru projekt CRM postal samo eden od neuspelih sodobnih projektov uvajanja informacijsko-komunikacijske tehnologije, ki jih $v$ današnjem času tržijo ponudniki storitev IKT, podjetja ali deli javnega sektorja pa jih pogosto začnejo uvajati brez širšega pogleda na celotno problematiko.

\subsection{CRM ali ravnanje odnosov s strankami v zasebnem sektorju}

Po Kovačiču (Kovačič, 2002, str. 70) je osnova koncepta ravnanja odnosov s strankami ugotovitev, da so za podjetje ključnega pomena kakovostni odnosi s strankami, ki so podlaga za obojestransko koristno in dolgoročno poslovno sodelovanje. Raziskave podjetja Gartner so pokazale ugotovitvi, ki govorita temu $\vee$ prid. Prva je, da je cena pridobivanja novih strank (oglaševanje, pospeševanje prodaje, neposredno trženje, razpisi) precej višja od cene zadrževanja obstoječih. Druga ugotovitev, ki govori v prid konceptu ravnanja odnosov s strankami, pa je, da obstoječe stranke z daljšim poslovnim sodelovanjem porabijo vedno več denarja za izdelke ali storitve določenega ponudnika, saj se na podlagi pozitivnih izkušenj ter dobrega odnosa s ponudnikom tveganje nakupa zmanjša, kar pomeni, da se bo stranka bolj verjetno odločila za vnovični ter najverjetneje večji nakup. 


\section{Nina Tomaževič \\ CRM v javnem sektorju: Kaj se lahko naučimo \\ iz izkušenj zasebnega sektorja?}

Ravnanje odnosov s strankami je torej celosten menedžerski pristop, ki ga omogoča tehnologija s široko usmeritvijo k stranki, in sicer za vzpostavitev, vzdrževanje in optimiziranje odnosov, s pomočjo katerih se pridobi stranko, da je bolj lojalna in dobičkonosna. Ravnanje odnosov s strankami zahteva k stranki usmerjeni poslovno filozofijo in kulturo, ki podpirata učinkovite trženjske, prodajne in storitvene procese. Koncept ravnanja odnosov s strankami lahko ločimo na tri dele, in sicer:

- sodelovalni del (odločitve o ustreznih kombinacijah komunikacijskih kanalov - prodajalne/okenca, telefon, mobilni telefon, internet, neposredni prodajalci - prek katerih komuniciramo s stranko)

- operativni del (usmerjanje procesov temeljne in podporne dejavnosti, npr. ERP)

- analitični del (organiziranje in interpretiranje podatkov o strankah, npr. rudarjenje podatkov) (Schellong, 2005, str. 327).

Osnovna načela ravnanja odnosov s strankami so prilagoditev zahtevam stranke (proizvodov, informacij, storitev), integracija (procesi planiranja, prenova poslovnih procesov, razvoj proizvodov in storitev), interakcija (kanali, dolgoročna komunikacija, raziskave) in selekcija (identificirati 20\% strank, ki prinesejo $80 \%$ dobička). Poleg naštetega sta za uspešen sistem ravnanja odnosov s strankami ključnega pomena ravnanje ob spremembah (change management) in strategija, ki promovira kulturo usmerjenosti k strankam.

\subsection{Ne le aplikacija, ampak način razmišljanja}

Izkušnje poslovnega sveta kažejo, da je (bilo) veliko projektov ravnanja odnosov s strankami neuspešnih. Napačno je namreč razmišljanje, da bo ena sama aplikacija rešila problem učinkovitega ravnanja s strankami in posledično prinesla večje prihodke ter prispevala $\mathrm{k}$ boljšemu poslovanju. Potreben je namreč celovit pristop k uvedbi takšne novosti, ki zahteva miselnost, da je ravnanje odnosov s strankami pot in ne cilj, ampak sredstvo za dosego ključnih ciljev v podjetju. Dober pristop naj bi vključeval (Moškon, 2003):

- podporo in vključenost najvišjih ravni menedžmenta pri vpeljavi in uporabi koncepta

- temeljito analizo in posodobitev poslovnih procesov, upoštevajoč potrebe strank

- ustrezno motiviranje in usposabljanje zaposlenih

- kakovostno integracijo tehnologije CRM v obstoječe tehnološko okolje. 


\section{CRM v javnem sektorju: Kaj se Nina Tomaževič \\ iz izkušenj zasebnega sektorja?}

Ključnega pomena je, da snovalci in izvajalci sprememb pridobijo zaupanje zaposlenih. Slednji se morajo namreč poistovetiti z novo poslovno miselnostjo, pripravljeni morajo biti sprejeti nov način obravnave strank, naučiti se morajo uporabljati novo tehnologijo in je ne obravnavati kot grožnjo svojemu delovnemu mestu.

\subsection{Vloga informacijsko-komunikacijske tehnologije}

$\checkmark$ primeru, da se podjetje odloči za uvedbo koncepta ravnanja odnosov $s$ strankami, je uporaba ustrezne podpore informacijsko-komunikacijske tehnologije nujna. Če podjetje posluje z majhnim številom dobaviteljev in strank, ne potrebuje kompleksne programske opreme za ravnanje $z$ informacijami in komuniciranje $z$ udeleženci $\vee$ poslovnem procesu. Velikim podjetjem pa ravno sodobna tehnologija omogoči prilagoditev odnosov na individualno raven, kar je $\checkmark$ konkurenčnem boju za stranke še kako pomembno.

Osnovna področja, ki jih je treba upoštevati in izvesti pri uvedbi izbranega orodja za ravnanje odnosov s strankami so (Kovačič, 2002, str. 71):

- baza podatkov (za napredno shranjevanje in poizvedbe po različnih kriterijih)

- učinkovit način pridobivanja podatkov

- vnos pravih podatkov $v$ bazo

- pravilna uporaba podatkov.

Iz naštetega je razvidno, da so ključni dejavnik uspešnega in učinkovitega ravnanja odnosov s strankami ljudje in šele nato informacijsko-komunikacijska tehnologija. Zadnje tri alineje prejšnjega odstavka namreč govorijo, da morajo pri pridobivanju, vnosu in uporabi podatkov sodelovati pravi ljudje, ki so za uspešno uvedbo in uporabo koncepta ravnanja odnosov s strankami ustrezno usposobljeni in motivirani.

Podjetja pridobivajo podatke o sedanjih, potencialnih in nekdanjih kupcih. Pravilno ravnanje s podatki iz kakovostne baze omogoča segmentacijo trga po različnih kriterijih, prilagajanje odnosov posameznim segmentom, prilagajanje ponudbe ter uporabo podatkov kjerkoli in kadarkoli.

Obstajajo pa tudi slabosti oz. pasti, ki jih je pri naložbah v orodja CRM treba upoštevati (Kovačič, 2002, str. 71):

- projekti informatizacije procesov niso usklajeni s poslovno strategijo (vedeti je treba, kdo so stranke, v katere segmente sodijo, katere potrebe in želje jim ponudba zadovoljuje, kaj naj se jim ponuja v prihodnje, po katerem prodajnem kanalu, na kakšne načine se z njimi komunicira, ipd.),

- projekti niso usklajeni z organizacijsko strukturo, 


\section{Nina Tomaževič \\ CRM v javnem sektorju: Kaj se lahko naučimo \\ iz izkušenj zasebnega sektorja?}

- $\quad$ različni deli informacijskega sistema niso povezani v učinkovito celoto.

Uvedba sodobnih orodij naj bi torej sledila postavitvi strategij in struktur in ne obratno. Dobra tehnološka podpora bo najverjetneje vplivala na strategijo in strukturo, vendar je pomemben vrstni red urejanja posameznih področij.

\section{Trendi v javnem sektorju}

\subsection{Usmerjenost k uporabniku}

Vse večja konkurenca $\vee$ zasebnem sektorju in hitra rast področja storitev sta vzpodbudila raziskave in usmeritev pozornosti strokovnjakov na teme, povezane s področjem ravnanja s strankami. Usmerjenost k strankam v zasebnem sektorju je imela/ima močan vpliv tudi na pričakovanja uporabnikov storitev javnega sektorja. Ideja o izboljšanju storitev javnega sektorja se je začela pojavljati $\vee$ poznih 70-ih letih prejšnjega stoletja z uveljavitvijo Novega javnega menedžmenta, vendar so ga mnogi razumeli preveč enostransko in so poudarjali le vidik ekonomske kontrole, brez upoštevanja procesov zagotavljanja storitev ter brez upoštevanja njihovih uporabnikov - državljanov in drugih subjektov. Ponovno se je usmerjenost $k$ uporabnikom začela poudarjati $\vee$ 90-ih letih prejšnjega stoletja, še posebej pod vplivom razmišljanja o državljanu kot stranki (Schellong, 2005, str. 326).

Tekavčičeva navaja (Tekavčič, 2004, str. 35), da se organizacije javnega sektorja že več kot dve desetletji spopadajo z okoljem, ki je sicer značilno za podjetja, ki $\vee$ konkurenčnih razmerah poslujejo po načelih tržnega gospodarstva. Ubadati se morajo z naraščajočimi pritiski na zmanjševanje stroškov ob hkratnih zahtevah po boljši kakovosti opravljenih storitev. Tako kot morajo podjetja slediti nenehno spreminjajočim se zahtevam strank, ki pričakujejo poceni, a visokokakovostne proizvode in storitve, morajo tudi organizacije javnega sektorja vse bolj upoštevati mnenja, potrebe in želje strank oz. uporabnike svojih storitev.

$\checkmark$ slovenskem prostoru je bilo do sedaj največ novosti uvedenih na področju državne uprave. Načela, ki so jih nosilci reform državne uprave postavili za svoj del javnega sektorja, bi lahko prenesli kar $v$ celoten javni sektor. Po Virantu (Virant, 2003, str. 67) je eno od načel, ki jih zasleduje reforma slovenske državne uprave, načelo usmerjenosti k uporabniku (stranki), s čimer želi državna uprava povečati zadovoljstvo strank s storitvami. Uporabnik storitev državne uprave namreč pričakuje, da bodo storitve, ki jih nudi državna uprava, 


\section{CRM v javnem sektorju: Kaj Nina Tomaževič iz izkušenj zasebnega sektorja?}

prostorsko in časovno lahko dostopne ter kakovostne in bodo o njih ustrezno informirani. Zaposleni v državni upravi pa naj bi skrbeli tudi za enostavnost postopkov, strokovnost, zanesljivost, lastno urejenost in urejenost poslovnih prostorov ter odzivnost na kritike, pripombe in predloge. Pogoj, ki pomembno vpliva na zadovoljstvo strank, pa je seveda zagotavljanje in spoštovanje "klasičnih « načel delovanja državne uprave kot so zakonitost, pravna varnost in predvidljivost, objektivnost, politična nevtralnost in odgovornost.

Po Virantu (Virant, 2003, str. 68) in Klunovi (Klun, 2004, str. 70) so v primeru javnega sektorja glavne ovire pri doseganju čim večje usmerjenosti k uporabniku (stranki) v tem, da:

- zadovoljstva stranke ne smemo postavljati pred interese drugih ali pred javni interes, ki ga določa zakon - torej stranka v primeru javnega sektorja nima vedno prav; kot primer navedimo nujnost obstoja represivnih organov;

- je stik z javnim sektorjem stranki večinoma manj prijeten kot če je v vlogi kupca proizvodov ali storitev zasebnega sektorja, zato je treba delovati tako, da se bodo zmanjševale za stranke stresne situacije, zniževali stroški postopkov ter izboljševale komunikacije in olajševal dostop do informacij;

- institucije javnega sektorja nezadovoljstvo strank ogroža bistveno manj kot podjetja, ki so neposredno odvisna od zadovoljstva strank. Vendar se na dolgi rok vodilne elite zavedajo pomembnosti zadovoljstva javnosti z delovanjem javnega sektorja, zato podpirajo in spodbujajo vse, ki so pripravljeni sodelovati pri uvajanju izboljšav procesov v javnem sektorju.

Kljub temu je veliko izzivov na področju izboljšanja odnosov s strankami v javnem sektorju in tudi $v$ Sloveniji se jih bo treba čim prej lotiti, ne samo $s$ predpisi in antibirokratskimi programi, ampak tudi z ustreznimi menedžerskimi ukrepi in z organizacijsko klimo ter organizacijsko kulturo, ki bo prijazna za zaposlene in za stranke.

\subsection{Drugi trendi v javnem sektorju - reorganizacija, privatizacija, globalizacija}

$\checkmark$ javnih sektorjih razvitih držav, na primer $\vee$ EU, ZDA, Avstraliji in Novi Zelandiji, so kot posledica reform vidne naslednje spremembe $v$ organiziranosti javnega sektorja (Pečar, 2002):

- drobitev velikih birokratskih organizacij v manjše enote, 


\section{Nina Tomaževič \\ CRM v javnem sektorju: Kaj se lahko naučimo \\ iz izkušenj zasebnega sektorja?}

- ločitev nabavne funkcije oz. financiranja od funkcije dobave oz. izvajanja storitev,

- nastanek novih oblik izvajalskih organizacij,

- $\quad$ prepustitev izvajanja javnih storitev majhnim izvajalcem, kot so: neprofitne organizacije, pogodbene upravne enote, zasebni izvajalci, neodvisne institucije, prostovoljne organizacije,

- zmanjševanje razlik med zasebnim in javnim sektorjem in posledičen razvoj sodobnih in podjetniško usmerjenih organizacij.

Tako spremenjena organiziranost kot uporaba modernih poslovnih in managerskih konceptov ter tehnologij naj bi $\vee$ prihodnje vplivali na to, da bi se tudi izvajanje javnih storitev globaliziralo. Pojavili naj bi se ponudniki s standardiziranimi storitvami, ki bi nudili enake storitve na vseh koncih sveta.

\subsection{E-uprava}

Ena od pomembnih izboljšav na področju delovanja javne uprave v mnogih sodobnih državah je pospešeno uvajanje e-uprave. S pristopom $\vee$ EU mora Slovenija prilagoditi in poenotiti tudi informacijsko infrastrukturo državnih organov. Vendar ne bo smelo ostati samo pri posodabljanju poslovanja državne uprave, ampak bo treba posodobiti in ustrezno informatizirati vse procese javnega sektorja, tako $v$ lokalni samoupravi kot $v$ drugih institucijah javnega sektorja (zavodi, agencije...).

Prednosti e-uprave so informatizirane in učinkovito povezane baze podatkov (registri, evidence) - G2G, s čimer se zagotavlja enostaven, hiter, kakovosten in poceni dostop do informacij in storitev javnega sektorja ter povezljivost evidenc in izmenjavo podatkov iz javnih evidenc.

Z e-upravo so torej informatizirani tisti deli poslovanja, ki jih država že izvaja oz. uporablja. Vendar jim bo treba dati dodatno uporabno vrednost in poiskati nova področja za izboljšave storitev, ki jih javni sektor nudi državljanom in drugim subjektom (G2C, G2B). Ob obstoječih bazah podatkov in procesih se bo $v$ naslednjem koraku torej treba vživeti $\vee$ vlogo stranke (državljana, gospodarskega subjekta) in njene življenjske situacije ter posodobiti procese $v$ javnem sektorju tako, da bodo ti učinkovito zadovoljevali potrebe državljanov in drugih subjektov $\checkmark$ državi.

Po Colnarju (Colnar, 2005, str. 6) bodo posodobitve zahtevale spremembe na različnih področjih in sicer na institucionalnem (spremembe zakonodaje), na vsebinskem (postopki, podatki), na organizacijskem (procesi in strukture, menedžment, kultura), kadrovskem (sistemizacija, usposabljanje) in informacijskem 
(e-uprava, baze podatkov, druge aplikacije, povezave). Iz navedenega sledi, da je koncept ravnanja odnosov s strankami širši in naprednejši od e-uprave, oboje pa lahko štejemo med orodja reform javnega sektorja.

\section{CRM v javnem sektorju}

\subsection{Opredelitev CRM (ravnanja odnosov s strankami) in CiRM (ravnanja odnosov z državljani)}

Pojav e-uprave je $\vee$ tujini $\vee$ poznih 90-ih letih prejšnjega stoletja pospešil reforme, usmerjene k Novemu javnemu menedžmentu, še posebej k iskanju rešitev, kako izboljšati storitve javnega sektorja s pomočjo "online« uporabniških programov. Istočasno so se $v$ literaturi pojavili prvi prispevki o uporabi koncepta ravnanja odnosov s strankami v javnem sektorju in sicer večinoma pri zasebnih svetovalnih družbah in družbah s panoge informacijsko-komunikacijske tehnologije, ki so zaradi že precejšnje zasičenosti trga $v$ zasebnem sektorju želele vpeljati koncept tudi na področje javnega sektorja.

Cilj ravnanja odnosov s strankami $v$ zasebnem sektorju je (Schellong, 2005, str. 328), zaradi zasledovanja osnovnega cilja podjetij, to je dobička, odkriti in zadržati najbolj dobičkonosne stranke. Javni sektor pa bo za razliko od zasebnega sektorja prek koncepta ravnanja odnosov s strankami skušal svojim strankam, torej državljanom, nuditi visoko kakovostne javne storitve. Pri tem je koncept stranke - uporabnika javnih storitev - drugačen od pojmovanja stranke $\checkmark$ zasebnem sektorju. Državljan je lahko namreč prejemnik storitev, partner pri pripravi storitev, nadzornik izvedbe ali davkoplačevalec. Uporabniki storitev javnega sektorja so $v$ različnih odnosih $s$ ponudniki storitev javnega sektorja, prav tako obstajajo razlike $v$ tem, kakšne so njihove možnosti vpliva na različne akterje v javnem sektorju in komuniciranja z njimi.

Za primer javnega sektorja so zato koncept ravnanja odnosov s strankami (CRM) nekateri avtorji preimenovali $\vee$ CiRM - Citizen Relationship Management (Ravnanje odnosov z državljani) ter ga opredelili kot strategijo, katere namen je obdržati in optimizirati odnose ter spodbujati državljanstvo (citizenship). To strategijo pa omogoča tehnologija s široko usmerjenostjo na državljane. CiRM je še vedno v zgodnji fazi razvoja in ima mnogo skupnega $z$ »upravo na enem mestu ", saj uspešna uvedba zahteva mrežno orientirano organizacijo, sodelovanje med ravnmi javne uprave oz. javnega sektorja, možnosti uporabe različnih komunikacijskih kanalov in prenovo javnih storitev ter z njimi povezane zakonodaje. 
Nina Tomaževič

CRM v javnem sektorju: Kaj se lahko naučimo

iz izkušenj zasebnega sektorja?

Tabela 3: Razlike med CRM v zasebnem in javnem sektorju

\begin{tabular}{|c|c|}
\hline zasebni sektor & javni sektor \\
\hline konkurenca & monopol \\
\hline tržna orientiranost & pravosodje \\
\hline milijon odnosov & milijoni/milijarde odnosov \\
\hline $\begin{array}{l}\text { homogeni proizvodi / storitve in obvla- } \\
\text { dljive količine }\end{array}$ & $\begin{array}{c}\text { veliko število različnih proizvo- } \\
\text { dov/storitev, neobvladljivo zaradi političnega } \\
\text { odločanja }\end{array}$ \\
\hline prilagoditev potrebam & pristop "enako za vse» \\
\hline $\begin{array}{c}\text { segmentacija (Paretovo pravilo } 20 \text { - } \\
\text { 80) }\end{array}$ & $\begin{array}{l}\text { segmentacija možna / nedobičkonosne } \\
\text { stranke niso izključene }\end{array}$ \\
\hline obstoječi sistemi IKT & obstoječi sistemi IKT \\
\hline \multirow[t]{2}{*}{ finančno planiranje/zniževanje stroškov } & $\begin{array}{c}\text { finančno planiranje (proračun) /zniževanje } \\
\text { stroškov }\end{array}$ \\
\hline & slab odnos do storitev \\
\hline \multirow[t]{2}{*}{ organizacijska kultura } & organizacijska kultura \\
\hline & $\begin{array}{l}\text { zaposleni (pomanjkanje znanj, plače } \\
\text { nekonkurenčne z zasebnim sektorjem) }\end{array}$ \\
\hline \multirow[t]{3}{*}{ zakonodaja } & zakonodaja \\
\hline & odgovornost / federalizem \\
\hline & politični vpliv (krog planiranja) \\
\hline $\begin{array}{l}\text { usmerjenost na dobiček / maksimiran- } \\
\text { je vrednosti za delničarja }\end{array}$ & demokratično razumevanje / filozofija \\
\hline
\end{tabular}

Vir: Schellong, (2005): “CRM in the Public Sector - Towards a conceptual research framework"

Koncept ravnanja odnosov s strankami v primeru javnega sektorja omogoča naslednje:

- zaposleni v javnem sektorju imajo dostop do podatkov o državljanih, medtem ko so lahko istočasno $v$ stikih z drugimi udeleženci ali gradijo druge podatkovne baze,

- uslužbenci lahko nudijo stranki bolj prilagojene storitve in informacije in lažje identificirajo morebitne probleme, 


\section{CRM v javnem sektorju: Kaj se Tomaževič iz izkušenj zasebnega sektorja?}

- uslužbencem na nižjih ravneh hierarhije je danih več pristojnosti in odgovornosti,

- $\quad$ sistem omogoča povezavo specialističnega znanja posameznika z nižjih ravni hierarhije s funkcijskimi znanji, kot so na primer strategija, komuniciranje, menedžment, zato se zaposleni počutijo manj izolirane in bolje informirane.

\subsection{Kaj se lahko javni sektor nauči od zasebnega}

Zadnje raziskave so pokazale, da ima $v$ primeru ravnanja odnosov s strankami tehnologija sama le zmeren do šibak vpliv na skupen uspeh naporov, ki jih podjetja usmerjajo $v$ gradnjo odnosov. Ključnega pomena je celostna filozofija usmerjenosti k uporabnikom. $\mathrm{V}$ javnem sektorju predstavljajo usmerjenost $\mathrm{k}$ uporabniku in skrb za njegovo zadovoljstvo aktivnosti, kot so sprememba delovnega časa, preoblikovanje prostorov za čakanje ali pa odprtje centrov, kjer lahko državljani uredijo vse na enem mestu, ter spremenjeno vedenje zaposlenih, ki pri vzpostavitvi stika s stranko vnaša osebnostno noto.

Izkušnje zasebnega sektorja kažejo, da propade kar 30 do $70 \%$ vseh poskusov uvedbe CRM v podjetja (Schellong, 2005, str. 328), predvsem zaradi neizkušenosti podjetij pri uvajanju tako kompleksnih sprememb, zaradi organizacijskih izzivov, odporov zaposlenih do sprememb ter zaradi pomanjkanja usklajevanja strategije in procesov. $V$ javnem sektorju se poleg navedenih ovir pojavljajo še omejeni proračuni, posebno na lokalni ravni. Povprečen projekt uvedbe koncepta ravnanja odnosov s strankami traja 2 leti, kar je z vidika politikov precej dolgo obdobje. Posebno zahtevni področji sta področje varovanja podatkov ter razmejitev potreb družbe od potreb posameznikov.

Javni sektor se bo moral pri uveljavljanju načela usmerjenosti k stranki/ državljanu zavedati naslednjih dejstev (Kost, 2005):

1. da pomeni k državljanu usmerjen javni sektor več kot le nudenje "samopostrežnih" storitev na internetu. $\vee$ ta namen bo treba:

- pri prenovi ponudbe storitev izhajati iz potreb strank in ne iz obstoječih procesov, podatkov in struktur,

- $\quad$ pri sestavljanju proračunov upoštevati izložke (output), ne vložkov (input);

2. da morajo biti storitve usmerjene k stranki/državljanu. Treba bo:

- identificirati najpogostejše skupne lastnosti strank posameznih institucij javnega sektorja,

- identificirati potrebe strank, 
Nina Tomaževič

CRM v javnem sektorju: Kaj se lahko naučimo

iz izkušenj zasebnega sektorja?

- poiskati rešitve za zadovoljitev potreb,

- identificirati kanale, prek katerih bo mogoče najbolje zadovoljiti potrebe,

- rešiti probleme, ki po nepotrebnem povečujejo kompleksnost;

3. da obstajajo mnogi vložki, ki vplivajo na storitve, zato bo treba:

- razumeti vplive političnih odločitev,

- $\quad$ ustvariti okolje, ki se bo odzivalo na zunanje vplive.

Osnovna izhodišča pri vpeljavi koncepta ravnanja odnosov s strankami oziroma z državljani so (Schellong, 2005, str. 329):

- obravnavanje državljana kot uporabnika javnih storitev (kakšna je psihologija državljana kot stranke, kako meriti zadovoljstvo državljana, ali bodo izboljšane storitve javnega sektorja imele vpliv na državljanstvo, katere kanale uporabljati, kako ocenjevati kakovost, katere podatke bodo državljani pripravljeni dati na voljo javnemu sektorju, kakšni bodo vplivi popolnoma vpeljanega CiRM na odnos med državljani in javnim sektorjem),

- poznavanje procesov javnega sektorja (obseg, stroški, vplivi, trajanje, akterji),

- razvoj ustreznih sistemov informacijsko-komunikacijske tehnologije (vplivi kanalov, razumevanje procesov, stroški, katere podatke zbirati),

- $\quad$ iskanje novih možnosti povezovanja različnih akterjev javnega sektorja na vseh ravneh (povezave, nove strukture, obstoječi podatki,

- $\quad$ razmišljanje o novih storitvah ob upoštevanju potreb in želja državljanov.

\subsection{Uvajanje sprememb in odpor zaposlenih}

Slovenska državna uprava in drugi deli javnega sektorja so se že večkrat lotili prenavljanja procesov, vendar je bilo veliko število dosedanjih poskusov neuspešnih. Pri planiranju in izvajanju takšnih projektov so se največkrat pojavljali naslednji problemi (Colnar, 2005):

- $\quad$ nerazumevanje pomembnosti izbire in dosledne uporabe ustreznega pristopa,

- težavno opredeljevanje vsebinskih/uporabniških zahtev,

- neprimerno sestavljene projektne skupine,

- izogibanje pristojnih oseb vrednotenju (vmesnih in končnih) rezultatov,

- težave pri uvajanju rešitev s področja informacijsko-komunikacijske tehnologije (nepripravljenost na spremembe). 


\section{CRM v javnem sektorju: Kaj se Nina Tomaževič iz izkušenj zasebnega sektorja?}

Tako kot velja za spremembe nasploh, se tudi pri uvajanju koncepta ravnanja odnosov s strankami pri ljudeh, ki sodelujejo ali bodo sodelovali pri uvedbi in uporabi omenjenega koncepta, pojavljajo strahovi, dvomi, previdnost, zavračanje, kritiziranje in druga čustva ter pojavi, ki ovirajo ali upočasnjujejo proces uvedbe novosti. Zaposleni bodo upravičeno skeptični, če bo ravnanje odnosov s strankami namesto premišljene in dobro pripravljene poslovne strategije le še ena izmed novih tehnologij oz. le eden izmed mnogih projektov, ki se $v$ zadnjem času pojavljajo kot poskusi izboljšav poslovanja.

Za uspešno vpeljavo koncepta in posledično rešitve je treba:

- zagotoviti popolno podporo in zavezanost menedžmenta,

- opredeliti cilje in poti za dosego le-teh,

- posodobiti procese poslovanja,

- podrobno se seznaniti s prednostmi in zahtevami novega koncepta,

- vse sodelujoče (zaposlene in stranke) seznaniti z njihovo vlogo in vplivom novosti nanje,

- vse sodelujoče ustrezno motivirati in jim pomagati spoznati, zakaj so spremembe potrebne in kje naj v novosti vidijo lasten interes in korist,

- prilagoditi finančne in nefinančne strukture nagrajevanja,

- vse sodelujoče ustrezno in pravočasno usposobiti za uporabo novosti ter za učinkovito komuniciranje s strankami,

- vzpostaviti kulturo storitev in kulturo širjenja znanja.

Nasveti, s pomočjo katerih lahko odgovorni za vpeljavo spremembe pridobijo na svojo stran vse vpletene za vpeljavo novosti, kot je uvedba koncepta ravnanja odnosov s strankami, so (prirejeno po Golob, 2002, str. 81):

- identificirati je treba "vplivneže«, ki podpirajo spremembo, z njihovo pomočjo predstaviti cilje in koristi novosti ter negativne posledice za posameznike ali organizacijo, do katerih bi prišlo, če sprememb(e) ne bi uvedli,

- zagotoviti je treba povratne informacije (zaposlene pozvati k sodelovanju, se jim zahvaliti, vzpostaviti dialog in upoštevati njihova mnenja),

- pripraviti je potrebno pravočasne predstavitve novosti in njihovih vplivov na vse vpletene ter zagotoviti redno in pogosto komunikacijo,

- ker ljudje potrebujejo stabilnost, jim je treba jasno razložiti tudi kaj se ne bo spremenilo, 


\section{Nina Tomaževič \\ CRM v javnem sektorju: Kaj se lahko naučimo \\ iz izkušenj zasebnega sektorja?}

- $\quad$ vpletene je potrebno seznaniti z dejstvi, $v$ nasprotnem primeru se bodo pojavile govorice in ugibanja,

- $\quad$ predvideti je treba morebitne probleme in jih predstaviti zaposlenim

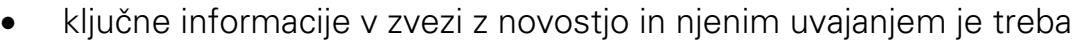
zapisati, saj to olajša komuniciranje o tem, kaj je nova strategija, kakšna je njena vloga in kaj pomeni za končne uporabnike,

- $\quad$ nagraditi je potrebno vse tiste, ki prilagodijo svoje vedenje zahtevam nove poslovne strategije.

\section{Zaključek}

V svetu večina uspešnih podjetij in vse več organizacij javnega sektorja že uveljavlja logiko poslovne odličnosti ter $v$ ta namen uporablja številne menedžerske koncepte in orodja, ki so jih za potrebe doseganja poslovne odličnosti razvili v poslovnem svetu. Tudi slovenski javni sektor se bo moral vse hitreje prilagajati spremembam $\vee$ okolju, tako s prenovo procesov kot struktur organiziranosti. E-uprava je le droben korak na poti k modernizaciji poslovanja državne uprave (kje je še preostali del javnega sektorja?), pa še ta pokriva le del obstoječih procesov in ne temelji na procesih, ki bi bili prenovljeni za potrebe sodobnega poslovanja .

Storitve sodobnega javnega sektorja naj bi torej bile cenejše od današnjih, prispevale naj bi $k$ razvoju gospodarstva in pomembno podpirale vladajoče strukture, prispevale $k$ boljši dostopnosti do kakovostnih informacij in povečevale transparentnost delovanja javnega sektorja. $\vee$ ta namen bo slednji moral razpolagati z uporabnimi, pravočasnimi in ažurnimi podatki za potrebe izboljšav na področjih kakovosti, ravnanja s strankami, ravnanja z ljudmi pri delu, ekonomike in financ ter tehnologije. Šele s takšno podporo bo možno izvajati osnovne funkcije učinkovitega in profesionalnega menedžmenta, kot so planiranje, organiziranje, vodenje in kontrola, ki so ključni elementi zagotavljanja sodobnega, odprtega in odzivnega javnega sektorja.

Če na koncu kot državljani in uporabniki storitev javnega sektorja razmišljamo o konceptu ravnanja odnosov s strankami kot o enem od menedžerskih pristopov, ki jih bo potrebno uvesti tudi v slovenski javni sektor, lahko upamo, da $\vee$ nobenem primeru ideja ne bo uveljavljena kot samo še ena (odvečna) moderna informacijsko-komunikacijska tehnologija, niti samo kot (predpisana) zahteva po prijaznem nasmehu javnega uslužbenca, ki ga $\vee$ precej primerih (še vedno) zaman pričakujemo. Koncept ravnanja odnosov s strankami bo prispeval pravo vrednost $h$ konkurenčnosti javnega sektorja in posledično 


\section{Nina Tomaževič \\ CRM v javnem sektorju: Kaj se lahko naučimo iz izkušenj zasebnega sektorja?}

cele države šele, če bodo ustrezno prilagojeni tako strateška usmeritev kot organizacijska kultura, struktura organiziranosti, procesi ter tehnologije vsakega dela javnega sektorja in bodo z njim in zaradi njega zadovoljni tako zunanji uporabniki - stranke (državljani in gospodarski subjekti) - kot notranji uporabniki. Prvim bo omogočil cenejše, hitrejše, prijaznejše in kakovostne storitve, drugim - lojalnim, zadovoljnim in motiviranim zaposlenim v javnem sektorju - pa prijazno in učinkovito delovno okolje.

Mag. Nina Tomaževič je na Fakulteti za upravo zaposlena kot asistentka od jeseni 2004, kjer sodeluje pri predmetih s področij organizacije, upravnega poslovanja, menedžmenta in ravnanja s človeškimi viri. Do zaposlitve na Fakulteti za upravo je 5 let delovala na vodstvenih mestih $v$ dveh največjih slovenskih podjetjih $s$ področja računalniških in informacijskih storitev.

\section{Literatura}

- Brown, S. A. (2000): "Customer Relationship Management", John Wiley \& Sons, Ontario

- Colnar, M. (2005): "Kje smo s prenovo procesov v naši upravi?”, XII. Dnevi slovenske uprave, Fakulteta za upravo

- Egan, J. (2001): "Relationship Marketing: Exploring relational strategies in marketing", Pearson Education, Harlow

- Golob, M. (2002): "Ko uvajate CRM, mislite na zaposlene", Gospodarki vestnik, letnik 51 , št. 36, str 80-81

- Klun, M. (2002): "Merjenje učinkovitosti in uspešnosti v javnem sektorju s poudarkom na davčni upravi", Doktorska disertacija, Univerza v Ljubljani, Ekonomska Fakulteta

- Klun, M. (2004): “Merjenje kakovosti, usmerjenost k uporabniku in davčna administracija", Uprava, letnik II, št. 1, str. 69-81

- Kovačič, D. (2002): "CRM - več kot modna muha", Kapital, letnik 11, št. 285, str. 70-71

- Kričej, D. (2002): "E-uprava na dlani", Založba Pasadena, Ljubljana

- Pečar, Z. (2002): "Model ocenjevanja uspešnosti delovnih procesov v javni upravi z uporabo nekaterih metod umetne inteligence", Doktorska disertacija, Univerza v Mariboru, Fakulteta za organizacijske vede, Kranj

- Pollit, C., Bouckaert, G. (1995): "Quality Improvement in European Public Services", Sage Publications, London

- Pollit, C., Bouckaert, G. (2004): "Public Management Reform", Oxford University Press, Oxford

- Postma, P. (2001): "Nova doba trženja", GV Založba, Ljubljana

- Schellong, A. (2005): "CRM in the Public Sector - Towards a conceptual research framework", http://www.ksg.harvard.edu/netgov/html/fellows_schellong_a.htm, december 2005 
Nina Tomaževič

CRM v javnem sektorju: Kaj se lahko naučimo

iz izkušenj zasebnega sektorja?

- Tekavčič, M., Peljhan D. (2004): "Pomen obvladovanja stroškov v javnem sektorju", Uprava, letnik II, št. 1, str. 31-47

- Virant, G. (2003): “Usmejenost k uporabniku kot načelo delovanja javne uprave", Uprava, letnik I, št. 2, str. 67-82

\section{Viri}

- Kričej, D. (2002): “e-Uprava danes in kako naprej”, Microsoft NT Konferenca, http://www.microsoft.si/slovenija/7ntk/Predstavitve/231b.ppt

- Kost, J. (2005): "The Government Customer Service Scenario", Gartner Symposium ITXPO, Orlando

- Moškon, S., Skube, M. (2003): “CRM - od besed k dejanjem”, Microsoft NT Konferenca, Portorož,

- $\quad$ http://www.ntk2003.microsoft.si/Slovenija/ntk2003/Predavanja/ppt/172.ppt, november 2005

- Uredba o upravnem poslovanju, Ur.I.RS, št. 20/2005, z dne 03. 03. 2005 


\section{SUMMARY}

\section{CRM in the Public Sector: What Can We Learn from the Experience of the Private Sector?}

The circumstances and the trends in the global economy require the national economies to develop and improve both competitive private and competitive public sector. All parts of Slovene public sector will sooner or later have to adapt to changes in the environment, starting to change old modes of thinking and use modern management tools and concepts. The article describes the concept of Customer Relationship Management which was developed in the private sector and tries to align the characteristics and the strengths of the concept with the current reforms of the processes and structures in the public sector.

In the western economies the majority of successful enterprises as well as more and more organizations from the public sector are already introducing the logics of business excellence and therefore use a number of modern managerial concepts and tools. Slovene public sector should act much faster as it does in order to adapt to changes in the environment, both through the modernization of the organizational processes and of the organizational structures. E-government is only a small step on the way to the modernization of the public administration (the rest of public sector is even more behind) but still this is not enough since e-government does not base on changed and modernized processes. It covers only a part of the existing processes and databases.

The services of a modern public sector should be cheaper than today, they should contribute to the development of the national economy and have an important role when supporting the governing structures. They should also contribute to the improved access to the information of a good quality and to the increased transparency of the activities of the public sector. For this purpose the public sector should have the access to useful, accurate and up-to-date data through which it should make significant improvements in quality, customer relationship management, human resource management, economics, finance and technology. These management processes will ensure the deployment of basic functions of efficient and professional management, such as planning, organizing, 
Nina Tomaževič

CRM v javnem sektorju: Kaj se lahko naučimo

iz izkušenj zasebnega sektorja?

leading and controlling. They are the key elements of a modern, open and responding public sector.

Looking from the citizen perspective and as users of the services of the public sector one can be sure that the concept of customer relationship management will have to be introduced also to the Slovene public sector. We only can hope that the idea will neither be realized as just another modern technology from the field of information-communications technologies nor as a requirement for the public servants' smile and kindness.

The concept of customer relationship management will add significant value to the competitiveness of the public sector and subsequently of the whole national economy only if also the strategic focus, organizational culture, the structure of the organizations, processes and technologies of each part of the public sector will be adjusted adequately. This will lead to the increased satisfaction of both external users - customers (citizens, enterprises) as well as internal users. The citizens and different business entities will therefore have the access to cheaper, faster, friendlier services of good quality and the employees will work in friendlier and efficient working environment which will increase their loyalty, motivation and satisfaction. 